\title{
WHAT MAKES THE EFFICACY AND EFFECTIVENESS OF MULTICULTURAL COUNSELING?
}

\author{
Herdi $^{1}$, Sunaryo Kartadinata and Agus Taufiq
}

\begin{abstract}
Today, multicultural counseling to be one of the most efficacy and effective helping professionals services in helping counselees achieve positive change. But, the critical question is what makes efficacy and effectiveness of multicultural counseling? The purpose of this study is to explore the factors affecting the efficacy and effectiveness of multicultural counseling. This study used a survey method. The participant included 30 pre-service counselor educators (master's students) from the Department of Guidance and Counseling in Universitas Negeri Jakarta. Data were collected using a questionnaire that is Common Factors in Multicultural Counseling Scale in the form of a Likert five-level scale. The data were analyzed with exploratory factor analysis. The results showed that there are two factors affecting the efficacy and effectiveness of multicultural counseling in the perspectives of pre-service counselor educators, named: (1) specific factors, such as: counseling approach and techniques and multicultural counseling competencies; and (2) common factors, such as: person of the counselor (wisdom) and counseling alliance. The implication is that counselor educators need to consider and develop these factors in Counselor Education and Supervision programs.
\end{abstract}

Keywords: Common Factors; Counselor Education and Supervision; Multicultural Counseling; Multicultural Counselors; Specific Factors

JOMSIGN: Journal of Multicultural Studies in Guidance and Counseling Website: http://ejournal.upi.edu/index.php/JOMSIGN

Permalink: http://ejournal.upi.edu/index.php/JOMSIGN/article/view/6314

How to cite (APA): Herdi, Kartadinata., \& Taufiq, A. (2019). What Makes the Efficacy and Effectiveness of Multicultural Counseling?. JOMSIGN: Journal of Multicultural Studies in Guidance and Counseling, 3(1), 1-14

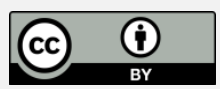

This is an open-access article distributed under the terms of the Creative Commons Attribution 4.0 International License, which permits unrestricted use, distribution, and reproduction in any medium, provided the original work is properly cited.

\section{INTRODUCTION}

Nowadays, counseling (including multicultural counseling) is one of the effective and effective professional services in helping counselees achieve positive change and overcome the problems they face (Kazdin, 2009; Kazdin \& Weisz, 2010; Miller, Hubble, Chow, \& Seidel, 2013; McLeod, 2007). A metaanalysis study found that counseling consistently proved effective and robust with an impact factor of .80 in helping counselees achieve positive change

\footnotetext{
${ }^{1}$ Universitas Negeri Jakarta; Herdi@unj.ac.id
} 
(Wampold, 2010; 2015; Lambert, 2017) and overcome counselee psychological disorders (Lambert, 2017).

Regardless of the consistency of these empirical findings, important and critical questions remain a matter of debate about what and how counseling works so as to produce positive changes in the counselee (Kazdin, 2009; Wampold, 2010; Wampold \& Imel, 2015). Experts (such as (Rosenzweig, 1936; Frank, 1961; Frank \& Frank, 1991; Wampold, 2001) conclude that "all counseling approaches are equally good and effective." The most important thing to consider so that the quality of counseling outcomes is guaranteed is "factors general factors "or" non-specific factors. "The meta-analysis reports that general factors have been shown to increase the efficacy and effectiveness of counseling (Imel \& Wampold, 2008; Leibert, 2011; Wampold, 2010; 2015; Wampold \& Imel, 2015 ) with impact factors ranging from .22 - .39 (Benish, Quintana, \& Wampold, 2011; Owen, Drinane, Idigo, \& Valentine, 2015) Even the results of other studies report the impact factors of common factors ranging from .46 - .57, while specific factors <.20 (Laska, Gurman, \& Wampold, 2014). The efficacy and effectiveness of counseling are influenced by $40 \%$ of counselee factors, $30 \%$ of general factors, and only $15 \%$ by counseling techniques ( Lambert, 2013; 2017) Contributions that are re A small point is shown by the specific technique of a particular theoretical orientation of counseling (Hansen \& Scholl, 2018) which ranges from 0 - 11\% (Wampold, 2001; Beutler, et al., 2004).

On the other hand, intensive studies on the factors that influence the efficacy and effectiveness of multicultural counseling are still limited. In fact, multicultural counseling is a necessity in a pluralistic and pluralistic society such as the Unitary State of the Republic of Indonesia. Previous meta-analysis studies found that multicultural counseling is more effective if it is relevant to the beliefs of counselee culture groups and adapts counseling techniques with impact factors .32 (Bennish, Quintana, \& Wampold, 2011). Based on this reasoning, the study aimed to explore the factors that influence the efficacy and effectiveness of multicultural counseling. The research question raised is: what factors influence the efficacy and effectiveness of multicultural counseling? The results of this study can enrich the theoretical foundation and praxis of multicultural counseling. 


\section{METHODS}

\section{Design}

The research method used is descriptive survey type because it is intended to explore various facts, opinions, attitudes, and certain behaviors (Heppner, Wampold, \& Kivlighan, 2008). In this study, things that are explored are general and specific factors that influence the effectiveness and efficacy of multicultural counseling from the perspective of prospective counselor educators (students of guidance and counseling masters).

\section{Participants}

Research participants numbered 30 prospective counselor educators (master students in guidance and counseling) at Jakarta State University. The study participants consisted of 7 (23.3\%) men and 23 (76.7\%) women.

\section{Data Collection Techniques}

Data on general and specific factors for multicultural counseling are collected using the General and Specific Factor Scale for Multicultural Counseling (SFUSKM). SFUSKM is independently developed by researchers based on general and specific factor constructs from the results of expert meta-analysis studies (Hubble, Duncan, Miller, \& Wampold, 2010; Lambert, 2013; Lambert \& Ogles, 2004; Wampold, 2015). This instrument measures two factors, namely general factors (5 items) and specific factors (4 items) that affect the effectiveness and efficacy of multicultural counseling. This instrument is in the form of a rating descriptor with a five-level Likert scale, ranging from $1=$ highly irrelevant to $5=$ very relevant. Test results using Rasch Model v. 3.73 all items fit because they meet the criteria of Mnsq Infit, Mnsq Outfit, Zstd, and Pt-M Corr, unidimensionality with Principle Component Analysis (PCA) of 55.9\%, and Cronbach's Alpha coefficient for test reliability including excellent (.88), participant reliability including good (.85), and the reliability of the item is sufficient (.75) (Linacre, 2019).

\section{Research Procedure}

Data collection was carried out traditionally using a paper and pencil questionnaire by visiting the participants directly in their respective campuses according to the agreed schedule. The researcher explains the purpose, asks for willingness, and conveys a guarantee of data confidentiality to the participants before filling out the research instrument. Participants are asked to fill in the 
instrument according to instructions. After the data is collected, the data is verified, processed and analyzed.

\section{Data Analysis Techniques}

Data analysis techniques used exploratory factor analysis (EFA). EFA is carried out with the aim of "testing a set of data into several dimensions, without the a priori specifications of a particular construct" (Heppner, Wampold, \& Kivlighan, 2008). In this research, EFA is used to explore and extract the factors that influence the effectiveness and efficacy of multicultural counseling in the view of prospective counselor educators (students of guidance and counseling masters).

\section{RESULTS AND DISCUSSIONS}

\section{Results}

This study aims to explore the factors that influence the effectiveness and efficacy of multicultural counseling according to the prospective counselor educator (student masters guidance and counseling) of Indonesia. In this study, EFA using the PCA extraction method and orthogonal rotation (varimax) was performed on nine factors of the effectiveness and efficacy of multicultural counseling. Verification of sample adequacy is carried out through the KaiserMeyer-Olkin (KMO) test and the correlation between items is carried out through Barlett's Test of Sphericity. The test results show a KMO value of .839, which means good because it far exceeds the minimum acceptable value of .5 (Field, 2009; Kaiser, 1974). Barlett's Test of Sphericity Results2 (30) = 135,056; $\mathrm{p}<.001)$ which indicates that the correlation between items is sufficiently large and sufficient to carry out PCA analysis. This means that there is sufficient data to conduct an EFA about the factors that influence the effectiveness and efficacy of multicultural counseling.

EFA test results using the PCA extraction method and orthogonal rotation (varimax) obtained by six counselors antecedents of wisdom that have an Eigen value $>1$ with a total variance obtained of $70,025 \%$. The variance that can be explained by factor 1 is $53,930 \%$ and factor 2 is $16,095 \%$. Given the sufficient sample size and convergence of the Scree Plots and Eigen value criteria, it can be determined from nine factors to be two factors that influence the effectiveness and efficacy of multicultural counseling from the perspective of prospective counselor educators (master students in guidance and counseling). 
Table 1

EFA Results on General and Specific Factors of Multicultural Counseling

\begin{tabular}{|c|c|c|c|c|c|}
\hline & \multicolumn{2}{|c|}{ Factor } & \multirow{2}{*}{$M$} & \multirow{2}{*}{$S D$} & \multirow{2}{*}{$\boldsymbol{h}$} \\
\hline & 1 & 2 & & & \\
\hline Compliance with counseling protocols (S3) & .877 & & 3.80 & .805 & .770 \\
\hline Differences in specific counseling techniques (S1) & .796 & & 3.60 & .724 & .646 \\
\hline $\begin{array}{l}\text { The special composition of specific counseling } \\
\text { techniques (S4) }\end{array}$ & .787 & & 3.67 & .661 & .791 \\
\hline $\begin{array}{l}\text { Counseling approaches, theories, and techniques } \\
\text { (C5) }\end{array}$ & .751 & & 3.83 & .791 & 677 \\
\hline Multicultural counseling competence (S2) & .739 & & 3.83 & .747 & .706 \\
\hline Counselor / extraterapeutic (C2) & & .846 & 4.00 & .871 & .717 \\
\hline $\begin{array}{l}\text { Personal counselor ("core conditions" and } \\
\text { wisdom) (C1) }\end{array}$ & & .833 & 4.33 & .661 & .744 \\
\hline Counseling Alliance (C3) & & .709 & 4.07 & .691 & .736 \\
\hline Placebo, expectations and expectations (C4) & & .653 & 3.83 & .648 & .614 \\
\hline Score Eigen & 4.854 & 1.449 & & & \\
\hline$\%$ Varians & 53.930 & 16.095 & & & \\
\hline
\end{tabular}

Table 1 presents two factors that influence the effectiveness and efficacy of multicultural counseling from the perspective of prospective counselor educators (students of guidance and counseling masters). The naming of these factors refers to the results of theoretical studies and relevant empirical findings. Factor 1, called specific factors, consists of (a) counseling approaches, models and techniques; and (b) multicultural counseling competencies; (c) adherence to counseling protocols; (d) add special compositions to specific counseling techniques; and (e) differences in specific counseling techniques. Factor 2 is called common factors, including: (a) personal counselor; (b) counseling alliance; (c) counselee/extra therapeutic; and (d) placebo, hopes and expectations.

\section{Discussion}

The study found that the effectiveness and efficacy of multicultural counseling are influenced by two main factors, namely specific factors, and common factors. The results of this study are relevant to the Common Factors theory "Dodo Bird Verdict" (Rosenzweig, 1936), Contextual Model "Bona Fide Psychotherapies" (Wampold, 2010; Wampold \& Imel, 2015), Efficacy and Effectiveness of Psychotherapy (Lambert \& Ogles, 2004), (Hubble, Duncan, Miller, \& Wampold, Introduction, 2010), and meta-analysis findings of metaanalysis findings (Lambert, 2013; Leibert, 2011; Lundh, 2014) that general factors of effectiveness and efficacy of counseling, include: (a) counselee/extra 
therapeutic; (b) placebo, hopes and expectations; (c) the quality of the counseling alliance; (d) counseling approaches, models or techniques; and (e) the personal quality of the counselor. The results of the study also support the findings of another meta-analysis from Wampold (Wampold, 2015) that general factors are important counseling elements in the contextual model, including alliances, empathy, cultural adaptation, expectations, and therapists (counselors). Meanwhile, specific factors that are important, include differences in care, competence, adherence to protocols, and special composition. However, the results of this study indicate that the approach, theory, or counseling technique is included as one of the specific factors rather than general factors such as previous theoretical and empirical studies.

General factors. These factors include: (a) personal counselor; (b) counseling alliance; (c) counselee / extra therapeutic; and (d) placebo, hopes and expectations. Personal counselor. Counselors are one of the most important and major general factors that contribute to counseling alliances and outcomes. A meta-analysis study found that the counselor's personal qualities had a strong effect on the medium category $(\mathrm{d}=.35 ; \mathrm{n}=29)$ in the clinical experiment scene and had a relatively large effect $(\mathrm{d}=.55 ; \mathrm{n}=17)$ in authentic and natural scenes towards alliances and counseling outcomes (Baldwin \& Imel, 2013). This finding raises questions about the personal characteristics and behavior of effective counselors. Experts affirm and find evidence that wisdom is the general factor of a comprehensive and effective personal counselor found in every counseling orientation that underlies the counseling alliance and the process of positive development and change counselee (Germer \& Siegel, 2012; Hanna, Bemak, \& Chung, 1999; Levitt \& Grabowski, 2019). Wisdom penetrates the "core conditions" (empathy, authenticity, unconditional positive acceptance) effective counselor personal, plays an important role as the fundamental quality of personality and the peak of counselor competence, as well as the main composition and new paradigm of effective multicultural counseling, although neglected in the counseling literature and research (Hanna \& Ottens, 1995; Hanna, Bemak, \& Chung, 1999).

The research concludes that wise and effective multicultural counselors are able to form and forge strong counseling alliances, have facilitative interpersonal skills, and develop and display professionalism (Wampold \& Imel, 2015; Osterlund LC, 2011; 2014), able to weigh, choose and take a wise decision. to various moral dilemmas vs. immoral and intrapersonal vs. interpersonal conflict (Thomas, et al., 2019) and effectively address complex 
complexities in the contemporary world (Sternberg, Nusbaum, \& Gluck, 2019). Wise multicultural counselors have also proven capable of adhering to the ethical principles of multicultural counseling (Herdi, Kartadinata, \& Taufiq, 2019), influencing peace of mind and peaceful behavior when dealing with conflicts with culturally diverse counselees (Herdi, Kartadinata, \& Taufiq, 2017a). , and avoid the behavior of "foolishness" that can threaten or hinder the achievement of benefit (Aczel, 2019; Sternberg \& Hagen, 2019; Sternberg, 2019).

Counseling alliance. The alliance consists of three main components, namely: emotional attachment, agreement on the goals and counseling tasks (Bordin, 1979; Dryden, 2008). The alliance is one of the most important factors in counseling. Alliances are usually measured at the beginning of the session (especially session 3 or 4 ) counseling. The alliance correlates and contributes significantly positively to the final outcome of counseling. A meta-analysis of 295 studies involving 30,000 counselees showed a significant positive relationship in the moderate category with $\mathrm{r}=.27$ or $\mathrm{d}=.57$ (Fluckiger, Del Re, Wampold, \& Horvath, 2018).

Counselor/extra therapeutic. This factor is a combination of internal resources (such as hope, motivation, ego strength, and psychological openness) and external counselee (such as social support, financial stability, and security) that can influence changes in the counseling process. The study found the counselor's "active" and "creative" roles ineffective counseling, including (a) involvement and participation; (b) positive perception of counseling; (c) agency, activity, reflexivity, and creativity; (d) integration of counseling experiences into daily life; and (e) earlier changes (Bohart \& Tallman, 2010).

Placebo, hope, and expectations. Expectations are an interesting topic to study in counseling. Expectations are the counselee's expectations of the benefits, procedures, the role of the counselor, and the duration and outcome of counseling (Arnkoff, Glass, \& Shapiro, 2002). A meta-analysis study reported that there was a relatively small but significant relationship between expectations and counseling outcomes $(\mathrm{d}=.24 ; \mathrm{n}=46)$ (Constantino, Arnkoff, Glass, Ametrano, \& Smith, 2011; 2011). Research (Connor \& Callahan, 2015) also found that $7.5 \%$ of counseling outcomes are influenced by the high expectations of counselees and counselors.

Specific factors. These factors include: (a) counseling approaches, models and techniques; and (b) multicultural counseling competencies; (c) 
adherence to counseling protocols; (d) add special compositions to specific counseling techniques; and (e) differences in specific counseling techniques. Counseling approaches, theories, and techniques. Theoretic approach factors and techniques are various orientation approaches or specific counseling procedures used by counselors. This factor emphasizes the main view that each counseling approach provides rational counselees to present problems, find new ways to define problems, find new ways to change or overcome problematic behavior patterns, and encourage them to try new ways to positively improve quality of life (Hubble, Duncan, Miller, \& Wampold, 2010). Factor models/counseling techniques provide a structure and method that is coherent with other general factors. Agreement on various counseling tasks and objectives will be guaranteed, if the theoretical orientation and counseling techniques are selected and used by the counselor in accordance with the counselee's outlook on life, resources, and skills.

Multicultural counseling competence. Multicultural counseling competence is one of the crucial issues in multicultural counseling. Competent multicultural counselors are characterized by (1) awareness of various assumptions, values, beliefs, outlook on life, and self-polemic and counselee culture accurately; (2) have knowledge and understanding of facts and information that are relevant to the outlook on life of the counselee population of different cultures; and (3) have skills in developing counseling strategies and techniques that are appropriate to the culture of the counselee (Herdi H., 2012; Sue \& Sue, 2016; Cornish, Schreiner, Nadkarni, Mczgger, \& Rodolfa, 2010). The strength of multicultural counseling lies in the counselee's acceptance of the counselor's explanation as an embodiment of the competency of the multicultural counseling he masters. A meta-analysis study found that multicultural counseling in accordance with the beliefs of counselee culture groups was more effective than those that did not adapt culture to the impact factors of .32 (Bennish, Quintana, \& Wampold, 2011).

Compliance with the counseling protocol. Effective counseling requires adherence to adequate protocols and competencies. A meta-analysis study found a small but significant positive effect on adherence to protocol $(\mathrm{d}=.02$; $\mathrm{n}=32)$ and competence $(\mathrm{d}=.07 ; \mathrm{n}=17)$ on counseling outcomes (Webb, DeRubeis, \& Barber, 2010).

Special composition. For some counselors, a modified counseling design is seen as the best way to identify the effects of specific compositions. A meta- 
analysis study showed that there was a very small, although significant $(\mathrm{d}=.01$; $\mathrm{n}=30$ ) difference between total care and treatment without one or more important compositions (Bell, Marcus, \& Goodlad, 2013; Ahn \& Wampold, 2001). Recent meta-analysis studies report that adding composition to certain treatments can increase the effect even if it is small $(\mathrm{d}=.28)$ on target variables (Bell, Marcus, \& Goodlad, 2013).

Differences in specific counseling techniques. The contextual model assumes that all counseling approaches and techniques that are structured and provided by an empathetic, caring, and facilitating counselee's positive involvement are predicted to have the same effect. A meta-analysis study found a significant positive correlation, although low $(\mathrm{d}=.20)$ between treatment factors and counseling outcomes (Wampold, 2015).

\section{CONCLUSIONS}

This research has produced factors that influence the effectiveness and efficacy of multicultural counseling. First, specific factors which include: (a) approaches, theories, and counseling techniques; and (b) multicultural counseling competencies; (c) adherence to counseling protocols; (d) add special compositions to specific counseling techniques; and (e) differences in specific counseling techniques. Second, general factors which include: (a) personal counselor; (b) counseling alliance; (c) counselee / extra therapeutic; and (d) placebo, hopes and expectations. This study finds it unique that the approach, model, or counseling technique is not a general factor in multicultural counseling, but rather is a specific factor. Another uniqueness is the counselor's personal factors (wisdom and "core conditions") and the counseling alliance is considered as a general factor with the highest average score compared to other factors. Further research is needed to examine the effect of these factors through correlational studies, involving a variety of participants (counselor educators, counselors, prospective counselors, and counselees) with their ethnicdemographic identity (gender, ethnicity, religious affiliation, education/training, and counseling experience) ), and use standardized measuring tools. The study of antecedents, measurements, consequences, as well as the development and testing of intervention programs to develop personal counselors (wisdom and "core conditions") and counseling alliances, are important in the education program and counselor supervision. 


\section{REFERENCES}

Aczel, B. (2019). Low levels of wisdom. In R. J. Sternberg, \& J. Gluck, The Cambridge handbook of wisdom (pp. 483-499). Cambridge: Cambridge University Press.

Baldwin, S. A., \& Imel, Z. E. (2013). Therapist effects: Finding and methods. In M. J. Lambert, Bergin and Garfield's handbook of psychotherapy and behavior (pp. 258-297). New York: John Wiley \& Sons.

Bell, E. C., Marcus, D. K., \& Goodlad, J. K. (2013). Are the parts as good as the whole? A meta-analysis of component treatment studies. Journal of Consulting and Clinical Psychology, 722-736.

Benish, S. G., Quintana, S., \& Wampold, B. E. (2011). Culturally adapted psychotherapy and the legitimacy of myth: A direct comparison metaanalysis. Journal of Counseling Psychology, 58, 279-289.

Bohart, A. C., \& Tallman, K. (2010). Clients: The neglected common factors in psychotherapy. In M. A. Hubble, B. L. Duncan, S. D. Miller, \& B. E. Wampold, The heart and soul of change: Delivering what works in therapy (2nd ed., pp. 83-111). Washington DC: American Psychological Association.

Bordin, E. S. (1979). The generalizability of the psychoanalytic concept of the working alliance. Psychotherapy: Theory, Research, and Practice, 16(3), 252-260.

Connor, D. R., \& Callahan, J. L. (2015). Impact of psychotherapist expectations on client outcomes. Psychotherapy (Chic), 351-362.

Constantino, M. J., Arnkoff, D. B., Glass, C. R., Ametrano, R. M., \& Smith, J. Z. (2011). Expectations. Journal of Clinical Psychology, 184-192.

Constantino, M. J., Glass, C. R., Arnkoff, D. B., Ametrano, R. M., \& Smith, J. Z. (2011). Expectations. In J. C. Norcross, Psychotherapy relationships that work: Evidence-based responsiveness (pp. 354-376). New York: Oxford University Press.

Cornish, J. A., Schreiner, B. A., Nadkarni, L. I., Mczgger, L. H., \& Rodolfa, E. R. (2010). Handbook of multicultural counseling competencies. Hoboken, New Jersey: John Wiley \& Sons.

Dryden, W. (2008). The therapeutic alliance as an integrating framework. In W. Dryden, A. Reeves, W. Dryden, \& A. Reeves (Eds.), Key issues for counseling in action (2nd ed., pp. 1-17). London: Sage Publications. 
Elliott, R., Bohart, A. C., Watson, J. C., \& Greenberg, L. S. (2011). Empathy. Psychotherapy, 43-49.

Elliott, R., Bohart, A. C., Watson, J. C., \& Greenberg, L. S. (2011). Empathy. In J. C. Norcross, Psychotherapy relationships that work: Evidence-based responsiveness (pp. 132-150). New York: Oxford University Press.

Farber, B. A., \& Doolin, E. M. (2011). Positive regard. Psychotherapy, 58-64.

Farber, B. A., \& Doolin, E. M. (2011). Positive regard and affirmation. In J. C. Norcross, Psychotherapy relationships that work: Evidence-based responsiveness (pp. 168-185). New York: Oxford University Press.

Field, A. (2009). Discovering statistics using SPSS (3rd ed.). London: Sage.

Fluckiger, C., Del Re, A. C., Wampold, B. E., \& Horvath, A. O. (2018). The alliance in adult psychotherapy: A meta-analytic synthesis. Psychotherapy, 48(1), 1-10.

Frank, J. D. (1961). Persuasion and healing: A comparative study of psychotherapy. Baltimore: Johns Hopkins University Press.

Frank, J. D., \& Frank, J. B. (1991). Persuasion and healing: A comparative study of psychotherapy. Baltimore: Johns Hopkins University Press.

Germer, C. K., \& Siegel, R. D. (2012). Wisdom and compassion: Two wings of a bird. In C. K. Germer, \& R. D. Siegel, Wisdom and compassion in psychotherapy: Deepening mindfulness in clinical practice (pp. 7-34). USA: The Guilford Press.

Hanna, F. J., \& Ottens, A. J. (1995). The role of wisdom in psychotherapy. Journal of Psychotherapy Integration, 5(3), 195-219.

Hanna, F. J., Bemak, F., \& Chung, R. C.-Y. (1999). Toward a new paradigm of multicultural counseling. Journal of Counseling \& Development, 77(2), $125-134$.

Hansen, J. T., \& Scholl, M. B. (2018). Introduction to modern perspectives on contemporary counseling issues. In M. B. Scholl, \& J. T. Hansen, Postmodern perspectives on contemporary counseling issues: Approaches across diverse settings (pp. 1-27). New York: Oxford University Press.

Herdi, H. (2012). Model pelatihan untuk meningkatkan kompetensi calon konselor multikultural. Jurnal Ilmiah VISI P2TK PAUD NI, 7(2), 107-116.

Herdi, H., Kartadinata, S., \& Taufiq, A. (2017a). Cultivating wisdom, harvesting peace: Strengthening multicultural counselor competencies for 
21st century. 1st International Conference on Educational Sciences. 2, pp. 318-326. Bandung: Scitepress.

Herdi, H., Kartadinata, S., \& Taufiq, A. (2017b). Faktor-faktor yang mempengaruhi kearifan konselor menurut perspektif calon konselor etnis Jawa. Jurnal Penelitian dan Evaluasi Pendidikan, 21(2), 162-174.

Herdi, H., Kartadinata, S., \& Taufiq, A. (2019). The influence of personal wisdom and multicultural wisdom on the adherence to the ethical principles of multicultural counselor's candidates. The 3rd International Conference on Learning Innovation and Quality Education (pp. 1-7). Solo, Indonesia: Atlantis Press.

Hubble, M. A., Duncan, B. L., Miller, S. D., \& Wampold, B. E. (2010). Introduction. In B. L. Duncan, S. D. Miller, B. E. Wampold, \& M. A. Hubble, The heart and soul of change: Delivering what works in therapy (pp. 1-46). Washington DC: American Psychological Association.

Imel, Z. E., \& Wampold, B. E. (2008). The importance of treatment and the science of common factors in psychotherapy. In S. D. Brown, \& R. W. Lent, Handbook of counseling psychology (4th ed., pp. 249-265). Hoboken, New Jersey: John Wiley \& Sons.

Kaiser, H. F. (1974). An index of factorial simplicity. Psychometrika, 39(1), 3136.

Kazdin, A. E. (2009). Understanding how and why psychotherapy leads to change. Psychotherapy Research, 418-428.

Kazdin, A. E., \& Weisz, J. R. (2010). Introduction: Context, backgrounds, and goals. In J. R. Weisz, \& A. E. Kazdin, Evidence-based psychotherapist for children and adolescent (2nd ed., pp. 3-9). New York: The Guilford Press.

Kolden, G. G., Klein, M. H., Wang, C.-C., \& Austin, S. B. (2011). Congruence/Genuineness. Psychotherapy, 65-71.

Kolden, G. G., Klein, M. H., Wang, C.-C., \& Austin, S. B. (2011). Congruence/Genuineness. In J. C. Norcross, Psychotherapy relationships that work: Evidence-based responsiveness (pp. 187-202). New York: Oxford University Press.

Lambert, M. J. (2013). The efficacy and effectiveness of psychotherapy. In M. J. Lambert, Bergin \& Garfield's handbook of psychotherapy and behavior change (pp. 169-218). Hoboken, New Jersey: John Wiley \& Sons.

Lambert, M. J. (2017). Maximizing psychotherapy outcome beyond evidencebased medicine. Psychotherapy \& Psychosomatics, 80-89. 
Laska, K. M., Gurman, A. S., \& Wampold, B. E. (2014). Expanding the lens of evidence-based practice in psychotherapy: A common factors perspective. Psychotherapy, 51(4), 467-481.

Leibert, T. W. (2011). The dimensions of common factors in counseling. International Journal for the Advancement of Counseling, 127-238.

Levitt, H. M., \& Piazza-Bonin, E. (2014). Wisdom and psychotherapy: Studying expert therapists' clinical wisdom to explicate common processes. Psychotherapy Research, 1-17.

Levitt, H. M., \& Grabowski, L. M. (2019). Professional wisdom: Functions and processes of psychotherapeutic and judicial wisdom. In R. J. Sternberg, \& J. Gluck, The Cambridge handbook of wisdom (pp. 676-697). Cambridge: Cambridge University Press.

Linacre, J. M. (2019). A user's guide to Winsteps and Ministep: Rasch-Model computer programs. Winsteps.com.

Lundh, L.-G. (2014). The search for common factors in psychotherapy: Two theoretical models with different empirical implications. Psychology and Behavioral Sciences, 3(5), 131-150.

Miller, S. D., Hubble, M. A., Chow, D. L., \& Seidel, J. A. (2013). The outcome of psychotherapy: Yesterday, Today, and Tomorrow. Psychotherapy, 8897.

Owen, J., Drinane, J. M., Idigo, C. K., \& Valentine, J. C. (2015). Psychotherapist effect in meta-analyses: How accurate are treatment effect? Psychotherapy, 52(3), 321-328.

Rosenzweig, S. (1936). Some implicit common factors in diverse methods in psychotherapy. American Journal of Orthopsychiatry, 412-415.

Sternberg, R. J. (2019). The critical important of wisdom in the world today. In R. J. Sternberg, \& J. Gluck, The Cambridge handbook of wisdom (pp. 39). Cambridge: Cambridge University Press.

Sternberg, R. J., \& Hagen, E. S. (2019). Teaching for wisdom. In R. J. Sternberg, \& J. Gluck, The Cambridge University Press (pp. 372-406). Cambridge: Cambridge University Press.

Sternberg, R. J., Nusbaum, H. C., \& Gluck, J. (2019). Applying wisdom to contemporary world problems. London: Palgrave MacMillan.

Sue, D. W., \& Sue, D. (2016). Counseling the culturally diverse: Theory and practice (7th ed.). Hoboken, New Jersey: John Wiley \& Sons. 
Thomas, M. L., Martin, A. S., Eyler, L., Lee, E. E., Macagno, E., Devereaux, M., ... Jeste, D. V. (2019). Individual differences in level of wisdom are associated with brain activation during a moral decision-making task. Brain and Behavior, 1(1), 1-14.

Wampold, B. E. (2010). The research evidence for the common factors models: A historically situated perspective. In B. L. Duncan, S. D. Miller, B. E. Wampold, \& M. A. Hubble, The heart and soul of change: Delivering what works in therapy (pp. 49-81). Washington DC: American Psychological Association.

Wampold, B. E. (2015). How important are the common factors in psychotherapy? An update. World Psychiatry, 270-277.

Wampold, B. E., \& Imel, Z. E. (2015). The great psychotherapy debate: The research evidence for what works in psychotherapy. New York: Routledge.

Webb, C. A., DeRubeis, R. J., \& Barber, J. P. (2010). Therapist adherence/competence and treatment outcome: A meta-analytic review. Journal of Consulting and Clinical Psychology, 200-211. 